Technical Note

\title{
Scale-Up Effects of $\mathrm{CO}_{2}$ Capture by Methyldiethanolamine (MDEA) Solutions in Terms of Loading Capacity
}

\author{
Samuel P. Santos ${ }^{1}$, João F. Gomes ${ }^{1,2, *}$ and João C. Bordado ${ }^{1}$ \\ 1 Centro de Recursos Naturais e Ambiente (CERENA), Instituto Superior Técnico, Universidade de Lisboa, \\ Av. Rovisco Pais, s/n, Lisboa 1049-001, Portugal; samuelpsantos@tecnico.ulisboa.pt (S.P.S.); \\ jcbordado@tecnico.ulisboa.pt (J.C.B.) \\ 2 Área Departamental de Engenharia Química (ADEQ), Instituto Superior de Engenharia de Lisboa, \\ Instituto Politécnico de Lisboa, R. Conselheiro Emídio Navarro 1, Lisboa 1959-007, Portugal \\ * Correspondence: jgomes@deq.isel.ipl.pt; Tel.: +351-21-8317-066; Fax: +351-21-8317-267 \\ Academic Editor: Manoj Gupta \\ Received: 4 March 2016; Accepted: 22 June 2016; Published: 28 June 2016
}

\begin{abstract}
In the present study, results from three different $\mathrm{CO}_{2}$ capture experimental scales (laboratory, pilot unit, and a larger pilot unit), using aqueous amine solutions of methyldiethanolamine (MDEA) $20 \mathrm{wt} \%$, are compared in terms of loading capacity. All three tested scales produced results regarding $\mathrm{CO}_{2}$ absorption using MDEA aqueous solutions, which were largely in accordance with the theoretical loading capacity of the used amine. Nevertheless, the observed differences between the theoretical and actual absorption behaviors of MDEA solutions for the different scales can be justified with the relative weight that process variables exhibit when the process is scaled up. Therefore, in order to achieve a correct scale-up of the process, simulations should be performed in order to define the best set of operational parameters in order to achieve high production yields and therefore more process profitability.
\end{abstract}

Keywords: carbon dioxide; chemical absorption; aqueous amine solutions; scale-up; methyldiethanolamine (MDEA)

\section{Introduction}

Environmental issues, due to the emissions of pollutants from combustion of solid, liquid, and gaseous fuels on various stationary and mobile energy systems, as well as the emissions from manufacturing plants, have contributed to major global problems involving not only pollutants such as sulphur, nitrogen oxides $\left(\mathrm{SO}_{\mathrm{x}}, \mathrm{NO}_{\mathrm{x}}\right)$, and particulate matter, but also greenhouse gases (GHG) such as carbon dioxide $\left(\mathrm{CO}_{2}\right)$ and methane $\left(\mathrm{CH}_{4}\right)$ [1]. Among $\mathrm{GHG}, \mathrm{CO}_{2}$ is the largest contributor, accounting for more than 60 percent of global warming effects, which is due to its high amount in the atmosphere [2].

The concept of separating $\mathrm{CO}_{2}$ from flue gas streams started to be applied in the 1970s, not only due to concerns about the greenhouse effect, but also as a potentially economic source of $\mathrm{CO}_{2}$, mainly for enhanced oil recovery (EOR) operations. Several commercial $\mathrm{CO}_{2}$ captures were constructed in the U.S. in the late 1970s and early 1980s. $\mathrm{CO}_{2}$ was also produced for other industrial applications such as the carbonation of brine and production of products such as dry ice, urea, and beverages $[3,4]$.

From the existing capture technologies, the only proven and mature technology is, currently, chemical absorption using aqueous amine solutions [5]. Chemical absorption is a well-known technology, and it has been widely deployed on a large scale across several industries [6].

In terms of solvent selection, amines have traditionally been considered as reagents of choice, whereas a primary alkanolamine, monoethanolamine (MEA), is typically considered the benchmark to 
which alternative solvents are compared. Other compounds that are often considered are piperazine (PZ), diethanolamine (DEA), and methyldiethanolamine (MDEA) [6].

One major setback in this process is that MEA has the limitation of a maximum $\mathrm{CO}_{2}$ loading capacity, based on stoichiometry of approximately $0.5 \mathrm{~mol} \mathrm{CO}_{2} / \mathrm{mol}$ amine-unlike tertiary amines such as MDEA, which has an equilibrium $\mathrm{CO}_{2}$ loading capacity nearly of $1.0 \mathrm{~mol} \mathrm{CO} 2 / \mathrm{mol}$ amine [7].

The mechanism involved in the absorption of $\mathrm{CO}_{2}$ by aqueous solutions of tertiary amines such as MDEA is somewhat different to those of primary and secondary amines, as they do not react directly with $\mathrm{CO}_{2}$. In fact, they act as a base, catalyzing the hydration of $\mathrm{CO}_{2}$. Thus, the reaction of interest in aqueous solutions of tertiary amines is

$$
\mathrm{CO}_{2}+\mathrm{H}_{2} \mathrm{O}+\mathrm{R}_{1} \mathrm{R}_{2} \mathrm{R}_{3} \mathrm{~N} \rightleftharpoons \mathrm{R}_{1} \mathrm{R}_{2} \mathrm{R}_{3} \mathrm{NH}^{+}+\mathrm{HCO}_{3}^{-} .
$$

Technologically, a typical chemical absorption process consists of an absorber and a stripper, in which the absorbent is thermally regenerated. In a chemical absorption process, as shown in Figure 1 [8], the flue gas containing $\mathrm{CO}_{2}$ enters a packed bed absorber from the bottom and contacts in counter-current with a $\mathrm{CO}_{2}$-lean absorbent. After absorption, the $\mathrm{CO}_{2}$-rich absorbent flows into a stripper for thermal regeneration. After regeneration, the $\mathrm{CO}_{2}$-lean absorbent is pumped back to the absorber as a cyclic mode. The pure $\mathrm{CO}_{2}$ released from the stripper is then compressed for the subsequent transportation and storage [3].

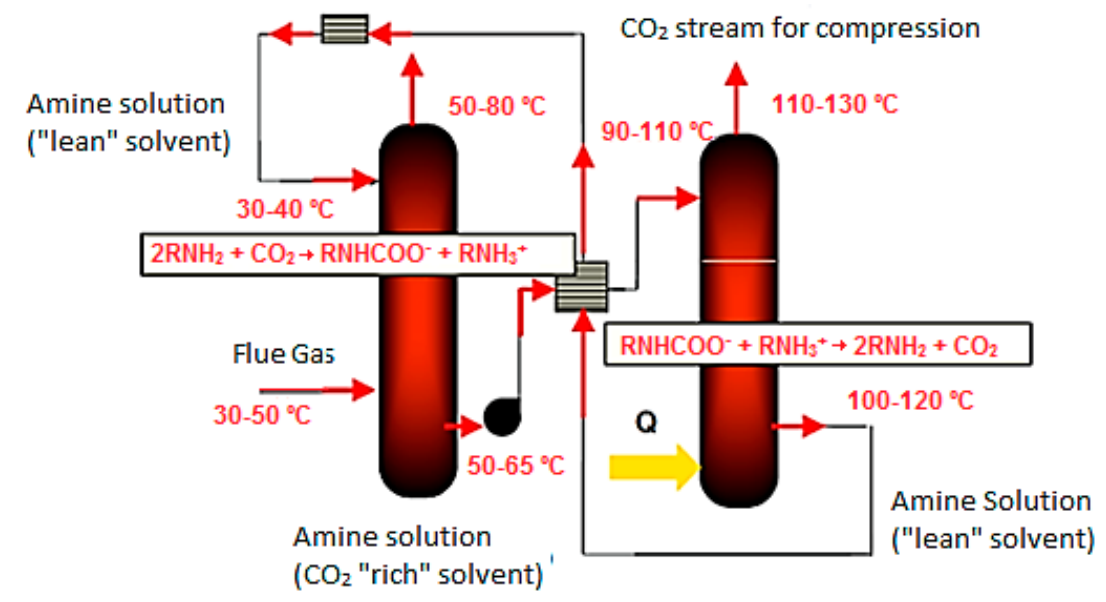

Figure 1. Process diagram for $\mathrm{CO}_{2}$ absorption using amines with the respective temperatures and reactions [8].

As stated by Arias [9], the main challenge for scaling-up is to progress from the experimental demonstration of the concept at an increasing scale and under realistic conditions, simultaneously validating the expected benefits and overcoming the obstacles that may appear in the path towards large-scale demonstration. In particular, the actual need to perform scale-up for $\mathrm{CO}_{2}$ absorption plants is considered critical [2], as the existing ones are not enough to deal with the current huge amount of $\mathrm{CO}_{2}$ emissions to the atmosphere. This requirement is related to both the $\mathrm{CO}_{2}$ flow rate and the loading capacity of solutions being used to absorb it [3].

In the present study, results from three different $\mathrm{CO}_{2}$ capture experimental scales (laboratory, pilot unit, and a larger pilot unit) in terms of loading capacity, using aqueous amine solutions of MDEA 20 $\mathrm{wt} \%$, are compared, following previous studies from the authors [10].

\section{Experimental}

For this study, on the behavior of MDEA solutions regarding $\mathrm{CO}_{2}$ absorption, three different experimental scales were used in order to collect consistent data, a laboratory scale, where a 500-mL 
three-necked flask was used, and two pilot-units, whose dimensions are shown in Table 1. All tests were performed at $1 \mathrm{~atm}$ and $20^{\circ} \mathrm{C}$.

Table 1. Dimensions of the absorption column used for the different scales.

\begin{tabular}{cccccc}
\hline Scale & $\begin{array}{c}\text { Column } \\
\text { Height }(\mathbf{d m})\end{array}$ & $\begin{array}{c}\text { Column Inner } \\
\text { Diameter }(\mathbf{d m})\end{array}$ & $\begin{array}{c}\text { Column } \\
\text { Volume (L) }\end{array}$ & $\begin{array}{c}\mathrm{CO}_{2} \text { Flowrate } \\
\text { (L/h) }\end{array}$ & $\begin{array}{c}\text { Aqueous Amine } \\
\text { Solution Flow (L/h) }\end{array}$ \\
\hline $\begin{array}{c}\text { Pilot-unit } \\
\text { Large pilot-unit }\end{array}$ & 15 & 0.505 & 3 & 1.2 & 24 \\
\hline
\end{tabular}

\subsection{Technique for $\mathrm{CO}_{2}$ Dosing}

For $\mathrm{CO}_{2}$ dosing, samples were collected from the absorption column through a sampling valve, in order to ascertain whether the solution was or was not saturated. The sample was then analyzed by the $\mathrm{BaCO}_{3}$ precipitation method. To use this method, the procedures described by Li et al. [11] and Santos [12] were followed: After the amine solution had been saturated with $\mathrm{CO}_{2}$, a sample of $20 \mathrm{~mL}$ was collected from the pilot unit. Then, a solution of sodium hydroxide $(\mathrm{NaOH}) 1.0 \mathrm{M}$, previously prepared from commercial sodium hydroxide (Solvay), was added in excess to the sample so that the dissolved $\mathrm{CO}_{2}$ was converted to non-volatile ionic species. Then, a solution of barium chloride dihydrate $\left(\mathrm{BaCl}_{2} \cdot 2 \mathrm{H}_{2} \mathrm{O}\right) 1.0 \mathrm{M}$, prepared previously from barium chloride dehydrate (Panreac Quimica Slu, Barcelona, Spain), was added in excess. The solution was well stirred to ensure that all the $\mathrm{CO}_{2}$ was absorbed, and was precipitated as barium carbonate $\left(\mathrm{BaCO}_{3}\right)$. Afterwards, the solution containing the precipitate was filtrated, dried, and weighted. The amount of precipitate was used to calculate the $\mathrm{CO}_{2}$ loading capacity as $\mathrm{CO}_{2}$ moles per mol of amine. The equations used in the calculations are as follows:

$$
w_{\text {amine }}=w_{\text {sample }} \times \%_{w},
$$

where

$w_{\text {amine }}$ is the amine weight $(\mathrm{g})$;

$w_{\text {sample }}$ is the weight of the sample collected from the pilot unit $(\mathrm{g})$;

$\%_{w}$ is the concentration of aqueous amine solution.

$$
n_{\text {amine }}=\frac{w_{\text {amine }}}{M W_{\text {amine }}},
$$

where

$n_{\text {amine }}$ is the number of moles of amine (mol amine);

$w_{\text {amine }}$ is the amine weight calculated before in Equation (1);

$M W_{\text {amine }}$ is the molecular weight of the amine $(\mathrm{g} / \mathrm{mol})$.

$$
n_{\mathrm{CO}_{2}}=\frac{m_{\text {precipitate }}}{\mathrm{MW}_{\mathrm{BaCO}_{3}}}
$$

where

$n_{\mathrm{CO} 2}$ is the number of moles of the obtained $\mathrm{CO}_{2}\left(\mathrm{~mol} \mathrm{CO}_{2}\right)$;

$m_{\text {precipitate }}$ is the weight of the obtained precipitate $(\mathrm{g})$;

$\mathrm{MW}_{\mathrm{BaCO} 3}$ is the molecular weight of $\mathrm{BaCO}_{3}(\mathrm{~g} / \mathrm{mol})$.

$$
\alpha=\frac{n_{\mathrm{CO}_{2}}}{n_{\text {amine }}}
$$

where

$\alpha$ is the $\mathrm{CO}_{2}$ loading capacity of the aqueous amine solution ( $\mathrm{mol} \mathrm{CO} 2 / \mathrm{mol}$ amine);

$n_{\mathrm{CO} 2}$ is the number of moles of the obtained $\mathrm{CO}_{2}$ calculated before as in Equation (3) $\left(\mathrm{mol} \mathrm{CO}_{2}\right)$; $n_{\text {amine }}$ is the number of moles of the amine calculated before as in Equation (2) (mol amine). 


\subsection{Laboratory Scale}

In a first stage, a laboratory-scale trial was performed to assess the maximum loading capacity of the prepared MDEA solution. A MDEA (Merck \& Co., Kenilworth, NJ, USA) aqueous solution (20 wt \%, with distilled water), was introduced in a flask. Initially, the system was purged with $\mathrm{N}_{2}$ for several minutes in order to remove any gaseous contaminants which could be possibly present. Then, $\mathrm{CO}_{2}$ (99.99\% Air Liquide, Paris, France) was carefully introduced into the flask to promote the saturation of the solution, as shown in Figure 2 [13]. Saturation was considered complete throughout the observation of the evolution of $\mathrm{CO}_{2}$ bubbles into the aqueous amine solution.

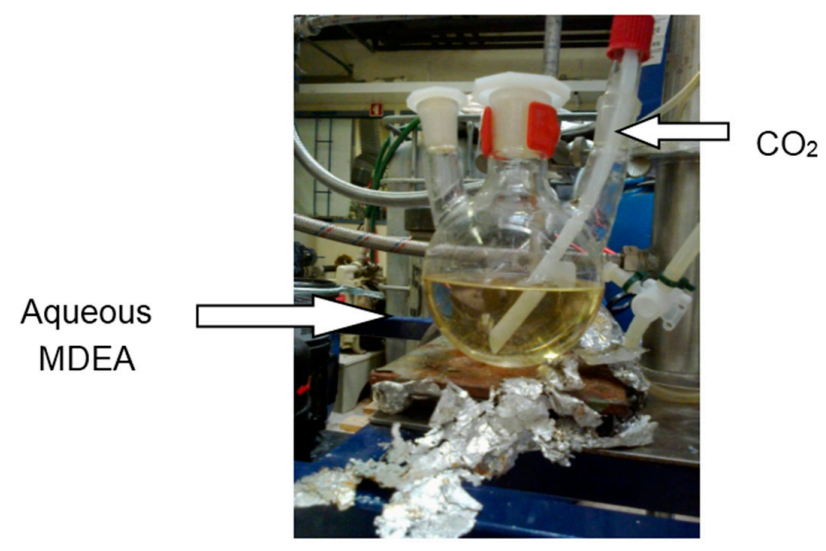

Figure 2. Illustration of experimental tests carried out to study the absorption of $\mathrm{CO}_{2}$ from aqueous amines solutions [13].

In order to determine the $\mathrm{CO}_{2}$ loading capacity of each aqueous amine solution under test until saturation, the method of barium chloride precipitation described in the previous section was used.

\subsection{Pilot Unit Scale}

In the following stage, in order to study the absorbing behaviour of MDEA in a carbon capture and separation system (CCS), two pilot units were used. Both units include an absorption column, as well as a stripping column, a heat exchanger between the two columns, a reboiler for the stripping column, pumping systems, surge tanks, and all necessary instrumentation and control systems.

The second stage of this study was performed using a smaller pilot unit in order to assess whether the results obtained in the trials of the first stage were still valid at a larger scale. The flowsheet of this unit is shown in Figure 3, and an actual picture is shown in Figure 4 [13].

To simulate the expected $\mathrm{CO}_{2}$ concentration in the gaseous streams, $\mathrm{CO}_{2}$ from a cylinder $(99.99 \%$ Air Liquide, Paris, France) (3) was mixed with air from a compressor (4). Then, the gaseous solution entered the absorption column (2) and contacted with the aqueous amine solution coming from the feed tank (1), and the chemical absorption of $\mathrm{CO}_{2}$ was able to take place. The gaseous stream leaving the top of the absorption column was connected to a $\mathrm{CO}_{2}$ analyzer (Witt Gastechnik GmbH \& Co KG, Witten, Germany) (8) so that the amount of $\mathrm{CO}_{2}$ existing in that stream could be measured. The cold liquid stream leaving the bottom of the absorption column flowed through a dosing pump (5) and then went through a heat exchanger (7) where it was heated. The liquid stream reached the top of the stripping column (6) where the $\mathrm{CO}_{2}$ release occurs. The gaseous stream, leaving the top of the stripping column, was connected to the stream leaving the top of the absorption column to the $\mathrm{CO}_{2}$ meter (8) so that the amount of $\mathrm{CO}_{2}$ in that stream could be also measured. The liquid stream leaving the stripping column at high temperature flowed through a dosing pump (5) and went through the heat exchanger (7), where it heated the stream leaving the bottom of the absorption column. This stream was cooled down in the heat exchanger and then went back into the feeding tank (1), where amine make-up was completed. Then, it entered the top of the absorption column (2), thus closing the 
cycle. The absorption column was filled with Berl saddles packing. Samples were collected just after the absorption column.

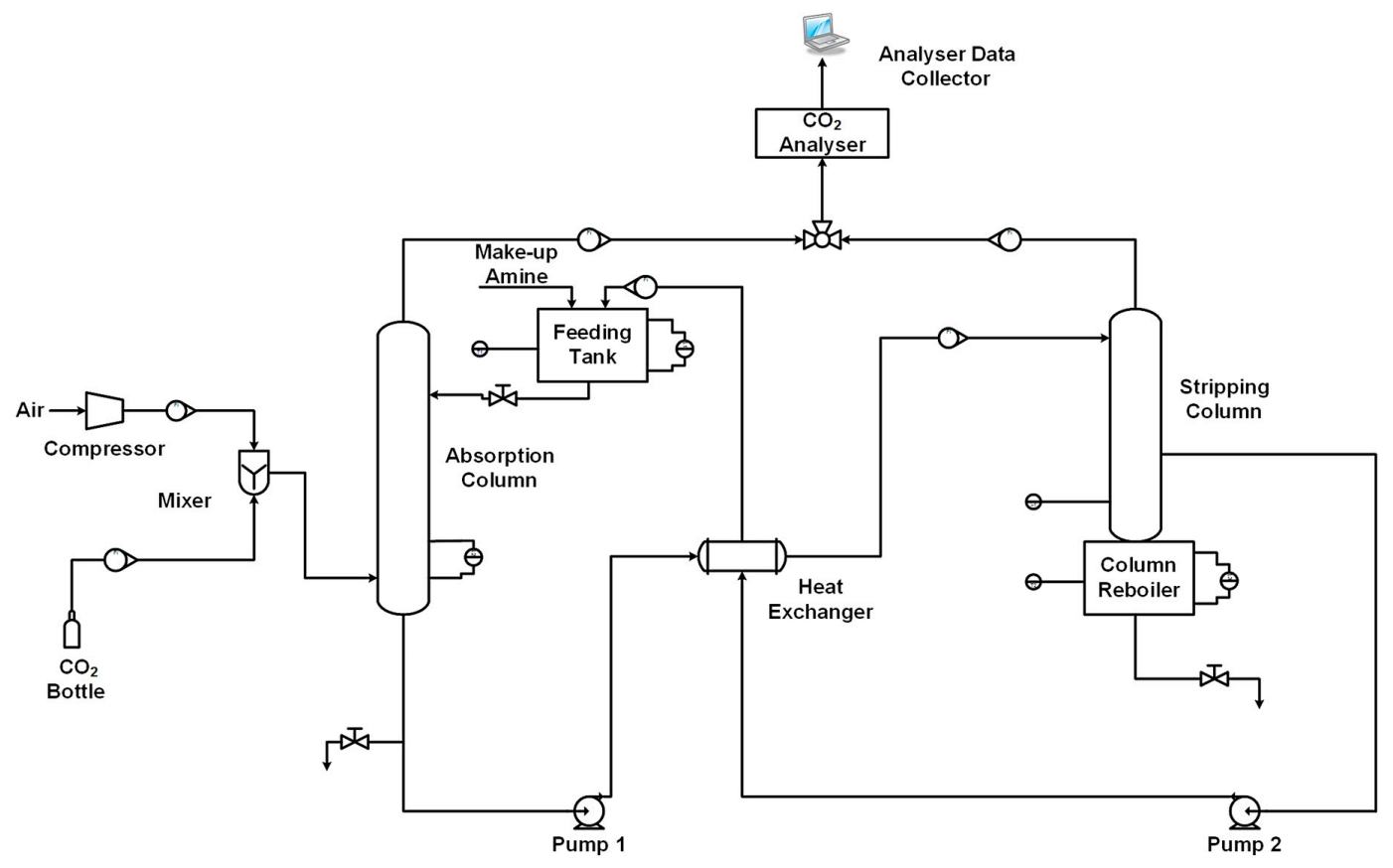

Figure 3. Flowsheet of the pilot units [13].

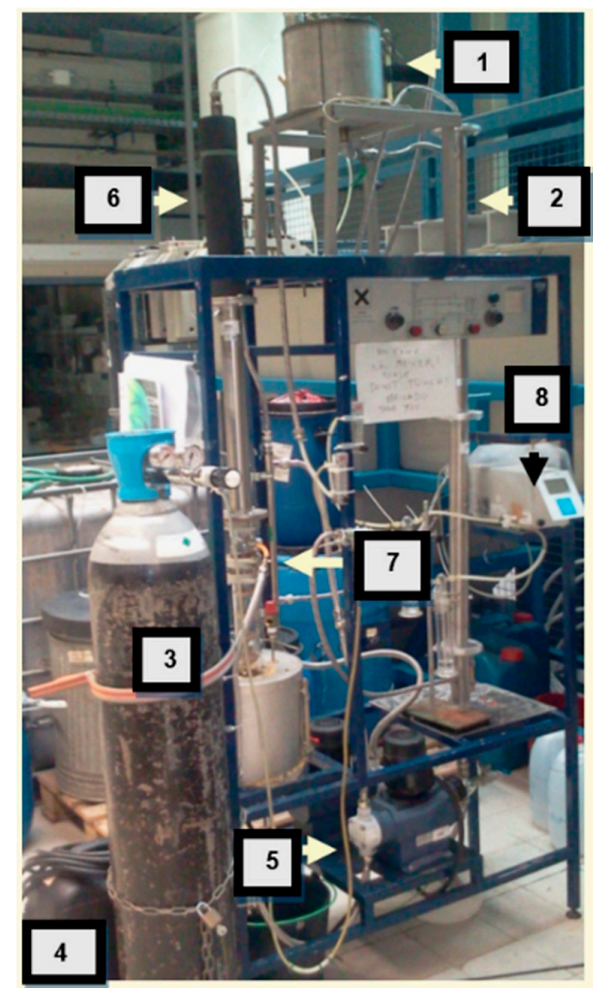

Figure 4. Small pilot unit [13] and its components: 1-Feeding tank; 2-Absorption column; 3- $\mathrm{CO}_{2}$ cylinder; 4-Air compressor; 5-Dosing pump; 6-Stripping column; 7-Heat exchanger; $8-\mathrm{CO}_{2}$ analyzer. 
In order to study the loading capacity of the amine under test, aqueous solutions $20 \mathrm{wt} \%$ were prepared and placed in the feeding tank. $\mathrm{CO}_{2}$ was then circulated jointly with the aqueous amine solution, and samples were collected every $30 \mathrm{~min}$ until the amine saturation was achieved. The amount of formed precipitate from the addition of $\mathrm{BaCl}_{2} \cdot 2 \mathrm{H}_{2} \mathrm{O}$ was used to calculate the $\mathrm{CO}_{2}$ loading capacity in terms of moles of $\mathrm{CO}_{2}$ per moles of amine, following the procedure previously described.

In the third stage, tests were performed in a larger pilot unit constructed in accordance with the same flowsheet, but using larger columns and higher flowrates. Moreover, due to the size of pilot unit, a closed circuit television (CCTV) system was installed so that, with the help of the monitors placed throughtout the pilot unit, it was possible to observe what was happening during the tests. A Berl saddles packing was placed inside the absorption column in order to enable better contact between the aqueous MDEA solution and the $\mathrm{CO}_{2}$ stream. $\mathrm{CO}_{2}$ flows jointly with the aqueous amine solution, and samples were collected every $30 \mathrm{~min}$ until the amine saturation was achieved, again after the absorption column. In order to determine the $\mathrm{CO}_{2}$ loading capacity by the aqueous MDEA solutions, the precipitation method was used again. A photo of this pilot unit was shown in Figure 5. Both units were operated so that the system achieves nearly a steady state.

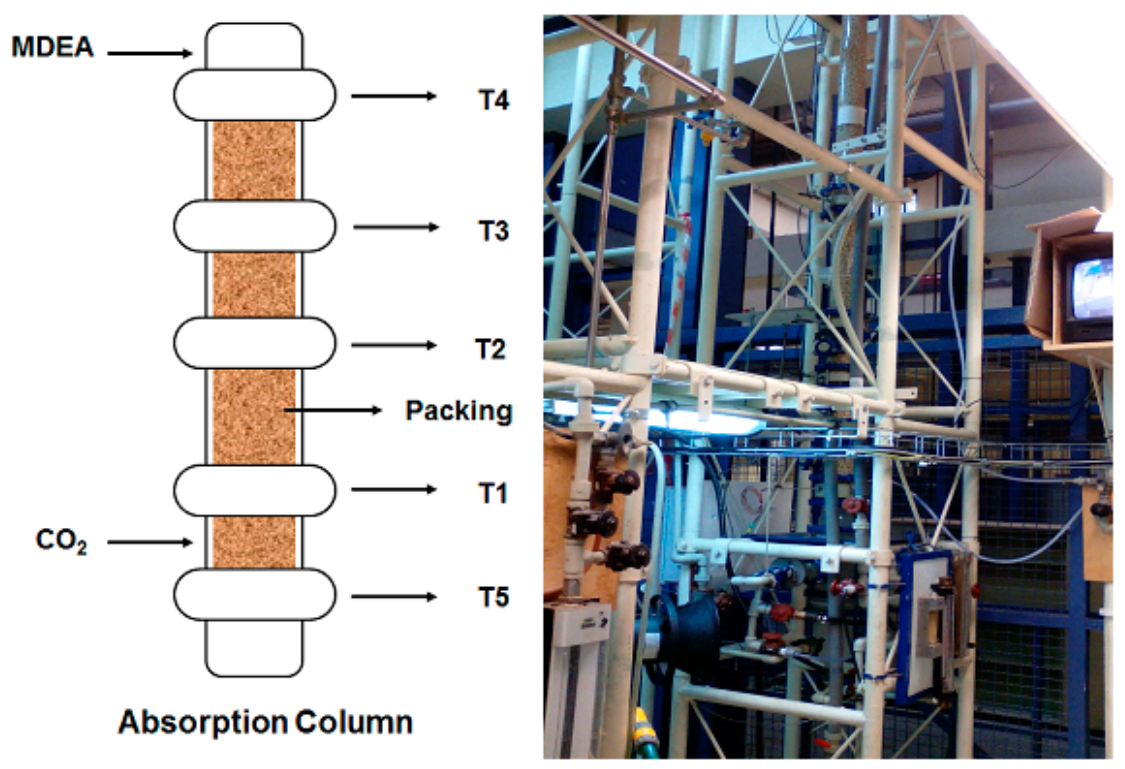

Figure 5. Large pilot unit and absorption column detail.

\section{Results}

\subsection{Results from Laboratory Scale}

In the laboratory scale trial performed using a 500-mL three-necked flask, the maximum loading capacity of the prepared MDEA solution was assessed. $\mathrm{CO}_{2}$ was bubbled inside the aqueous MDEA solution until it was saturated. This process took around four hours to be achieved.

Using the precipitation method, as described before, the loading capacity of the saturated MDEA solution, after four hours, was determined to be $0.979 \mathrm{~mol} \mathrm{CO}_{2} / \mathrm{mol}$ amine. This value can be used as a benchmark to compare the results obtained in both pilot units. The results presented here, as well as the ones for the other scales described thereafter in Section 3.2, are the averaged values from a series of three tests each.

\subsection{Results from Pilot Unit Scale}

For the smaller pilot unit, using the same dosing method, the obtained results are shown in Table 2 and represented graphically in Figure 6. 


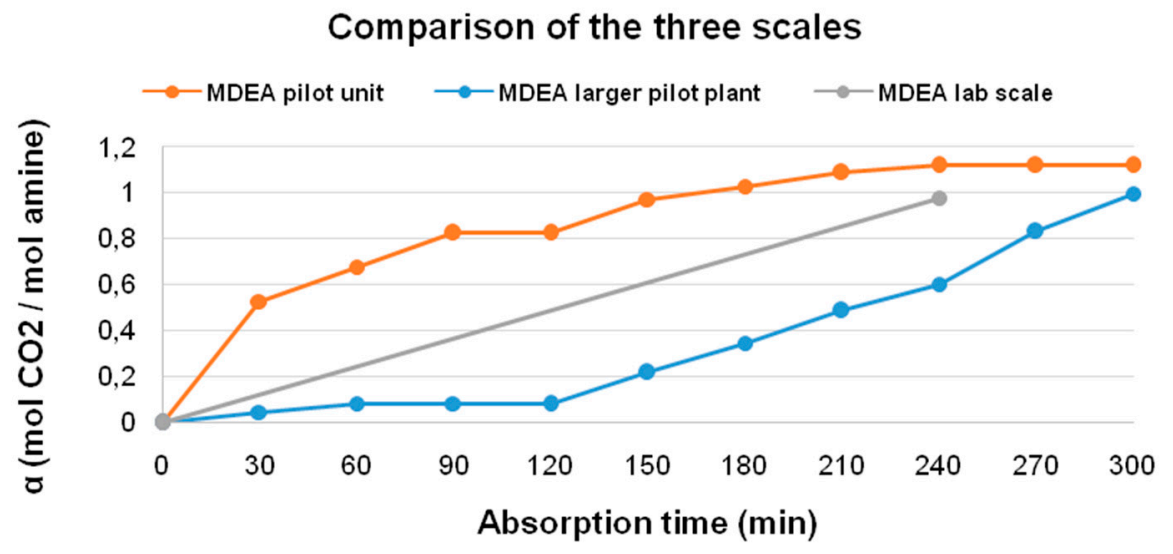

Figure 6. Comparison of the obtained results for $\mathrm{CO}_{2}$ loading capacity $(\alpha)$ over the absorption time for the tested aqueous MDEA solution (20 wt \%) in the three different testing scales.

Table 2. Results from $\mathrm{CO}_{2}$ absorption by the aqueous methyldiethanolamine (MDEA) solution at $20 \%$ $(w / w)$ in the small pilot unit.

\begin{tabular}{cc}
\hline Absorption Time (min) & $\begin{array}{c}\text { Loading Capacity }(\alpha) \\
\text { (mol CO } \mathbf{C O}_{\mathbf{2}} / \mathbf{m o l} \text { amine) }\end{array}$ \\
\hline 30 & 0.529 \\
60 & 0.676 \\
90 & 0.824 \\
120 & 0.824 \\
150 & 0.971 \\
180 & 1.029 \\
210 & 1.089 \\
240 & 1.118 \\
270 & 1.118 \\
300 & 1.118 \\
\hline
\end{tabular}

In the tests performed in the larger pilot plant, the precipitation method was also used to determine the $\mathrm{CO}_{2}$ loading capacity by the aqueous MDEA solutions in order to assess whether the results obtained in this pilot unit would be in accordance with the ones obtained in the small pilot unit. The obtained results are shown in the Table 3 and graphically in Figure 6.

Table 3. Results from $\mathrm{CO}_{2}$ absorption by the aqueous MDEA solution at $20 \%(w / w)$ by the precipitation method in the larger pilot unit.

\begin{tabular}{cc}
\hline Absorption Time (min) & $\begin{array}{c}\text { Loading Capacity }(\alpha) \\
\left(\mathbf{m o l ~ C O}_{\mathbf{2}} / \mathbf{m o l} \text { amine) }\right.\end{array}$ \\
\hline 30 & 0.046 \\
60 & 0.084 \\
90 & 0.082 \\
120 & 0.079 \\
150 & 0.218 \\
180 & 0.347 \\
210 & 0.486 \\
240 & 0.602 \\
270 & 0.831 \\
300 & 0.998 \\
\hline
\end{tabular}




\section{Discussion}

\subsection{Laboratory Scale}

It should be noted that MDEA is a tertiary amine and does not react directly with $\mathrm{CO}_{2}$, but acts as a base, catalyzing the hydration of $\mathrm{CO}_{2}$, which means that its equilibrium $\mathrm{CO}_{2}$ loading capacity is approximately $1.0 \mathrm{~mol} \mathrm{CO} / 2 \mathrm{~mol}$ amine. Therefore, the results obtained at laboratory scale ( $\alpha=0.979 \mathrm{~mol} \mathrm{CO}_{2} / \mathrm{mol}$ amine) are consistent with what was to be expected $[7,14]$.

\subsection{Pilot Unit Scale}

When analyzing the obtained results, it can be concluded that, by using the smaller pilot unit, it was possible to achieve a $\mathrm{CO}_{2}$ absorption profile nearly in accordance with the theoretical basis, whereas the MDEA aqueous solution reached $\mathrm{CO}_{2}$ saturation around the 240th min; although the actual obtained value was slightly higher than it was expected $\left(1.0 \mathrm{~mol} \mathrm{CO}_{2} / \mathrm{mol}\right.$ amine $)$, this could be attributed to the experimental inaccuracy of the precipitation method used to determine $\mathrm{CO}_{2}$. Comparing the obtained results for the three scales, which are graphically shown in Figure 6, marked differences appear between the absorption patterns regarding the tests performed in each pilot unit. It should be noted that, although the loading capacity is still increasing, in the larger pilot unit, from the 270th to the 300th min, it seems to be enough, for comparison purposes, to use the loading capacity at $300 \mathrm{~min}$ of operation.

These differences may result from process scale-up. In fact, scaling up any process can result in several difficulties for chemical engineers due to the fact that the relative importance of process variables affecting performance considerably increases. In fact, process variables, such as $\mathrm{CO}_{2}$ injection point in the absorption column, reactant flow, contact time between the reactants throughout the absorption column, temperature and pressure control, and maintenance, have a marked influence on the performance of the units. These variables are somewhat easier to control at laboratory scale and at a small pilot unit, but its significance becomes considerably relevant for larger scales, as noticed by Zlokarnik [15]. This can be easily concluded by comparing the results from both pilot plant units presented in this paper. Although theoretically at the same pressure and temperature (two variables which were kept constant for all performed tests), the saturated $\mathrm{CO}_{2}$ loading should be the same, regardless of the scale used. However, this does not happen in practice, as demonstrated by this study. In this study, other variables such as column internal packing, pressure drops, residence time, and flooding conditions were kept approximately constant, in spite of scale differences. Nevertheless, it should be noted that, for this preliminary analysis, mass transfer coefficients have not been calculated.

As stated in Table 1, the small pilot unit has a column height of $15 \mathrm{dm}$, while the larger pilot unit has a column height of $110 \mathrm{dm}$, representing an increase of 7.3 times, and the inner column diameter increased from $0.505 \mathrm{dm}$ to $0.750 \mathrm{dm}$ in the larger pilot unit, representing an increase of 1.5 times. This results in quite different volumes for the columns of $3 \mathrm{~L}$ in the small pilot unit and $62 \mathrm{~L}$ in the larger pilot unit, which represents a scale increase of 20.7. In such a larger volume, it is much more difficult to obtain a good mixing contact between the gas phase $\left(\mathrm{CO}_{2}\right)$ and the liquid phase (aqueous amine solution); therefore, the system $\mathrm{CO}_{2}$ loading capacity $(\alpha)$ will be much slower to reach equilibrium, as observed in this study, as shown in Figure 6. Furthermore, the maximum obtained for the latter situation is even lower than the one obtained in the small pilot plant.

These scale-up effects are, in fact, quite difficult to quantify but tend to considerably affect the performance of the absorption process, particularly when progressing for even larger scales, such as industrial plants, as pointed out by previous authors $[3,4]$.

However, a way to decrease the significance of the inconvenient scale-up effects will be to complement the scaling-up process by additionally including the use of simulation tools in order to help in the selection of the best operating conditions for the process, contributing to high production yields and thus a more profitable operation, as required for the integration of CCS within current production processes [16]. In fact, the use of steady-state or dynamic models for simulation, taking into 
account precise geometry factors of the columns, as well as operating factors such as the flow rate of each phase, could help to reduce the inaccuracy of the estimation process, as suggested by Panahi and Skogestad [17]. Particular care should be taken in the scale-up of chemical processes involving unit operations such as absorption and stripping, which are, in fact, affected by a multitude of operational factors, apart from dimensional ones.

Acknowledgments: The authors gratefully acknowledge the support from the KIC Inno Energy Project: ACoPP-Advanced Near-Zero Emissions Coal-Fired Plant-and thank Jorge Rodrigues de Carvalho (IST) for laboratory and equipment utilization. No funds were received to cover publication costs.

Author Contributions: João C. Bordado and João F. Gomes conceived and designed the experiments. Samuel P. Santos performed the experiments. All authors were involved in the analysis of data, the discussion of results, and the writing of the paper. All authors have read and approved the final manuscript.

Conflicts of Interest: The authors declare no conflict of interest.

\section{References}

1. Song, C. Global challenges and strategies for control, conversion and utilization of $\mathrm{CO}_{2}$ for sustainable development involving energy, catalysis, adsorption and chemical processing. Catal. Today 2006, 115, 2-32. [CrossRef]

2. Yang, H.; Xu, Z.; Fan, M.; Gupta, R.; Slimane, R.; Bland, A.; Wright, I. Progress in carbon dioxide separation and capture: A review. J. Environ. Sci. 2008, 20, 14-27. [CrossRef]

3. Yu, C.; Huang, C.; Tan, C. A review of $\mathrm{CO}_{2}$ capture by absorption and adsorption. Aerosol Air Qual. Res. 2012, 12, 745-769. [CrossRef]

4. Rao, A.; Rubin, E. A technical, economic and environmental assessment of amine-based $\mathrm{CO}_{2}$ capture technology for power plant greenhouse gas control. Environ. Sci. Technol. 2002, 36, 4467-4475. [CrossRef] [PubMed]

5. Figueroa, J.; Fout, T.; Plasynski, S.; Mcllvried, H.; Srivastava, R. Advances in $\mathrm{CO}_{2}$ capture technology-The U.S. Department of Energy's Carbon Sequestration Program. Int. J. Greenh. Gas Control 2008, 2, 9-20. [CrossRef]

6. MacDowwell, N.; Florin, N.; Buchard, A.; Hallet, J.; Galindo, A.; Adjiman, C.; Williams, C.; Shah, N.; Fennell, P. An overview of $\mathrm{CO}_{2}$ capture technologies. Energy Environ. Sci. 2010, 3, 1645-1669. [CrossRef]

7. Supap, T.; Idem, R.; Tontiwachwuthikul, P.; Saiwan, C. Kinetics of sulfur dioxide and oxygen-induced degradation of aqueous monoethanolamine solution during $\mathrm{CO}_{2}$ absorption from power plant flue gas streams. Int. J. Greenh. Gas Control 2009, 3, 133-142. [CrossRef]

8. Gomes, J. Sequestração de $\mathrm{CO}_{2}$-Uma Visão Integrada das Tecnologias Químicas Disponíveis. Habilitation Thesis, Universidade Técnica de Lisboa, Lisboa, Portugal, 2010. (In Portuguese).

9. Arias, B.; Diego, M.; Abanades, J.; Lorenzo, M.; Dias, L.; Martínez, D.; Alvarez, A.; Sánchez-Biezma, A. Demonstration of steady state $\mathrm{CO}_{2}$ capture in a $1.7 \mathrm{MW}_{\text {th }}$ calcium looping pilot. Int. J. Greenh. Gas Control 2013, 18, 237-245. [CrossRef]

10. Gomes, J.; Santos, S.; Bordado, J. Choosing amine-based absorbents for $\mathrm{CO}_{2}$ capture. Environ. Technol. 2015, 36, 19-25. [CrossRef] [PubMed]

11. Li, M.; Chang, B. Solubilities of carbon dioxide in Water + Monoethanolamine + 2-Amino-2-methyl-1-propanol. J. Chem. Eng. Data 1994, 39, 448-452. [CrossRef]

12. Santos, A. Estudos de Absorção de $\mathrm{CO}_{2}$ em Soluções Aminadas. Master's Thesis, Instituto Superior de Engenharia de Lisboa, Lisboa, Portugal, 2012. (In Portuguese).

13. Santos, S.; Gomes, J.; Bordado, J. Comparative Study of Amine Solutions Used in Absorption/Desorption Cycles of $\mathrm{CO}_{2}$; LAP Lambert Academic Publishing: Saarbrucken, Germany, 2014.

14. Budzianowski, W. Single solvents, solvent blends and advanced solvent systems in $\mathrm{CO}_{2}$ capture by absorption: A review. Int. J. Glob. Warm. 2015, 7, 184-225. [CrossRef]

15. Zlokarnik, M. Scale up in Chemical Engineering, 2nd ed.; Wiley-VCH: Weinheim, Germany, 2006. 
16. Budzianowski, W. Low-carbon power generation cycles: The feasibility of $\mathrm{CO}_{2}$ capture and opportunities for integration. J. Power Technol. 2011, 91, 6-13.

17. Panahi, M.; Skogestad, S. Economically efficient operation of $\mathrm{CO}_{2}$ capturing process part I: Self-optimizing procedure for selecting the best controlled variables. Chem. Eng. Process. 2011, 50, 247-253. [CrossRef]

(c) 2016 by the authors; licensee MDPI, Basel, Switzerland. This article is an open access article distributed under the terms and conditions of the Creative Commons Attribution (CC-BY) license (http:/ / creativecommons.org/licenses/by/4.0/). 